\title{
Blended and more: instructors organize sensemaking opportunities for mathematical equations in different ways when teaching the same scientific phenomenon
}

\author{
Fang Fang Zhao ${ }^{1}$, Linh Chau $^{2}$ and Anita Schuchardt ${ }^{3 *}$ (D)
}

\begin{abstract}
Background: Many students solving quantitative problems in science struggle to apply mathematical instruction they have received to novel problems. The few students who succeed often draw on both their mathematical understanding of the equation and their scientific understanding of the phenomenon. Understanding the sensemaking opportunities provided during instruction is necessary to develop strategies for improving student outcomes. However, few studies have examined the types of sensemaking opportunities provided during instruction of mathematical equations in science classrooms and whether they are organized in ways that facilitate integration of mathematical and scientific understanding. This study uses a multiple case study approach to examine the sensemaking opportunities provided by four different instructors when teaching the same biological phenomenon, population growth. Two questions are addressed: (1) What types of sensemaking opportunities are provided by instructors, and (2) How are those sensemaking opportunities organized? The Sci-Math Sensemaking Framework, previously developed by the authors, was used to identify the types of sensemaking. Types and organization of sensemaking opportunities were compared across the four instructors.

Results: The instructors provided different opportunities for sensemaking of equations, even though they were covering the same scientific phenomenon. Sensemaking opportunities were organized in three ways, blended (previously described in studies of student problem solving as integration of mathematics and science resources), and two novel patterns, coordinated and adjacent. In coordinated sensemaking, two types of sensemaking in the same dimension (either mathematics or science) are explicitly connected. In adjacent sensemaking, two different sensemaking opportunities are provided within the same activity but not explicitly connected. Adjacent sensemaking was observed in three instructors' lessons, but only two instructors provided opportunities for students to engage in blended sensemaking.

(Continued on next page)
\end{abstract}

\footnotetext{
* Correspondence: aschucha@umn.edu

${ }^{3}$ Department of Biology Teaching and Learning, College of Biological Sciences, University of Minnesota-Twin Cities, 5-210H Moos Tower, 515

Delaware Street, SE, Minneapolis, MN 55455, USA

Full list of author information is available at the end of the article
}

\section{Springer Open}

() The Author(s). 2021 Open Access This article is licensed under a Creative Commons Attribution 4.0 International License, which permits use, sharing, adaptation, distribution and reproduction in any medium or format, as long as you give appropriate credit to the original author(s) and the source, provide a link to the Creative Commons licence, and indicate if changes were made. The images or other third party material in this article are included in the article's Creative Commons licence, unless indicated otherwise in a credit line to the material. If material is not included in the article's Creative Commons licence and your intended use is not permitted by statutory regulation or exceeds the permitted use, you will need to obtain permission directly from the copyright holder. To view a copy of this licence, visit http://creativecommons.org/licenses/by/4.0/. 


\begin{abstract}
(Continued from previous page)
Conclusions: Instructors provide different types of sensemaking opportunities when teaching the same biological phenomenon, making different resources available to students. The organization of sensemaking also differed with only two instructors providing blended sensemaking opportunities. This result may explain why few students engage in the successful strategy of integrating mathematics and science resources when solving quantitative problems. Documentation of these instructional differences in types and organization of sensemaking provides guidance for future studies investigating the effect of instruction on student sensemaking.
\end{abstract}

Keywords: Instruction; Blended sensemaking; Mathematical equations; Sensemaking; Population growth

\section{Introduction}

Mathematical equations are routinely used in science to represent scientific phenomena (Bialek \& Botstein, 2004; Brush, 2015; Lazenby \& Becker, 2019). Thus, policy documents in science education advocate that students should use quantitative reasoning and mathematical modeling to study complex physical systems with mathematical equations (American Association for the Advancement of Science, 2011; NGSS Lead States, 2013). However, students struggle with using equations in solving quantitative problems in science and fail to make connections between the equation and the scientific phenomenon (Becker \& Towns, 2012; Bing \& Redish, 2009; Stewart, 1983; Taasoobshirazi \& Glynn, 2009; Tuminaro \& Redish, 2007). These difficulties have been attributed to a lack of opportunities provided for sensemaking of mathematical equations in science during instruction (Bing \& Redish, 2008; Lythcott, 1990; Schuchardt \& Schunn, 2016). However, little research exists on sensemaking related to mathematical equations in science classes and whether there are differences in the sensemaking opportunities instructors provide to students. Characterization of these differences allows for informed design of studies that address the effect of different sensemaking opportunities during instruction on student problem-solving and learning. This study examines the sensemaking opportunities provided by college biology instructors when teaching mathematical equations on the same biology phenomenon.

\section{Literature review}

Mathematics plays a critical role in scientific research and science education. Although students have been exposed to mathematics before they entered college, they still struggle with making sense of mathematical equations learned in science class. Mathematics in mathematics classes are different than the mathematics in science classes (Redish \& Kuo, 2015), and the sensemaking of mathematical equations in science needs to connect to both disciplines, the science and the mathematics. Research on science sensemaking and mathematics sensemaking has been limited to its own disciplinary community. The science education community refers to scientific sensemaking as constructing explanations for scientific phenomena (Kapon, 2016; Odden \& Russ, 2019), while the mathematics education community refers to mathematics sensemaking as developing a sense of mathematical practice in the process of learning different types of mathematical knowledge (Rittle-Johnson \& Schneider, 2015; Schoenfeld, 1992).

In both science and mathematics education, there are calls to move practices away from memorization of terminology and facts and repetitive application of procedural algorithms for solving problems. Instead, the emphasis is on providing opportunities for students to engage in sensemaking and authentic disciplinary practices (Li \& Schoenfeld, 2019; NGSS Lead States, 2013). The space instructors provide for students during instruction affects what knowledge students can make sense of and how students construct their knowledge during classes (Marton, Runesson, \& Tsui, 2004). According to Li and Schoenfeld (2019), instruction needs to shift toward providing students experiences that foster their sensemaking of mathematics and science and away from the memorization of facts or procedures. However, instruction of mathematical equations in science, particularly in biology, has generally not been systematically characterized.

Multiple types of scientific knowledge and mathematical knowledge are embodied in mathematical equations in science. The scientific knowledge includes the entities and processes relevant to the scientific phenomenon represented by the equations, while the mathematical knowledge includes the syntax and semantics used to express meaning (Zhao \& Schuchardt, 2021). Sensemaking of equations can occur using either scientific or mathematical resources or the scientific and mathematical knowledge may be merged to generate a blended sensemaking (Bain, Rodriguez, Moon, \& Towns, 2019; Eichenlaub \& Redish, 2019; Fauconnier \& Turner, 1998; Zhao \& Schuchardt, 2021).

The idea of blended sensemaking originates from the field of cognitive science where it has been defined as a cognitive operation that draws upon two separate mental resources/spaces to create a third mental resource/space which is greater than the sum of its parts (Fauconnier \& Turner, 1998). Blended sensemaking has been adopted 
as a lens for analyzing student problem solving while using equations in science (Bain, Rodriguez, Moon, \& Towns, 2018; Bing \& Redish, 2007; Eichenlaub \& Redish, 2019; Kuo, Hull, Gupta, \& Elby, 2013). In this context, blended sensemaking has come to mean that students are drawing on both their knowledge of mathematics and their knowledge of science when solving mathematical equations in science. For example, when solving a physics problem, a student first interprets the mathematical structure of an equation to indicate that the final velocity will be equal to the initial velocity plus the change due to acceleration. She is then able to accurately reason that if one ball has a velocity of $2 \mathrm{~m} / \mathrm{s}$ when a second ball is dropped, then $5 \mathrm{~s}$ later the first ball will be faster than the second ball by $2 \mathrm{~m} / \mathrm{s}$ because there is no additional force other than gravity after the balls are dropped and gravity is acting on both balls equally. This process of connecting the mathematical meaning with the events occurring in the physical phenomenon is referred to as blended sensemaking (Kuo et al., 2013).

Currently, in the study of mathematical equations in science, blended sensemaking has generally been treated as a singular entity. However, hints have occurred that blended sensemaking may be more complex (e.g., Bain et al., 2018; Bing \& Redish, 2007). Bain et al. (2018) described the blended sensemaking of two students as low quality and high quality. The student who engaged in "low-quality" blended sensemaking discussed ideas about how the concentration of reactants in a reaction would change over time and stated that it is based on the dissociation equation. However, he did not make explicit connections between the mathematical meaning of the equation and the events in the chemical phenomenon. In contrast, another student, who was described as engaged in "high-quality" blended sensemaking, explicitly related the mathematical meaning embedded in the equation to events happening in the chemical phenomenon. He explicitly related the chemistry phenomenon that reactants are consumed to produce products to first the mathematical meaning of a negative slope and then the meaning of rate in the equation. In our prior work, we developed a framework for categorizing sensemaking of mathematical equations in science along two dimensions (mathematical and scientific) (Zhao \& Schuchardt, 2021). According to this framework, the low-quality sensemaking described by Bain et al. (2018) is occurring solely in the science dimension, because after a reference to an equation, the sensemaking is only in the science space. The science sensemaking is likely cued by some features of the mathematical equation, but it is not clear what these features are or if the student has consciously made sense mathematically of the equation as opposed to just perceiving a general form. Based on our framework, the second student described above as engaging in "high-quality" sensemaking by Bain et al. (2018) is engaging in sensemaking of the equation separately in the mathematical dimension and in the science dimension as well as a third level of sensemaking where he combines the mathematical sensemaking and science sensemaking of the equation. In this paper, we reserve the term "blended sensemaking" of equations for this combined sensemaking along both dimensions.

Students who tend to blend mathematical and chemical resources when solving equations in chemistry are more likely to identify multiple problem-solving approaches (Bain et al., 2018). In physics and biology, students who spontaneously blend resources when solving mathematical equations are often able to make progress solving complex and novel problems (Redish \& Kuo, 2015; Schuchardt, 2016). However, many students even when they have the appropriate mathematical and scientific knowledge fail to blend these resources when solving mathematical problems (Becker \& Towns, 2012; Bing \& Redish, 2009; Schuchardt, 2016; Stewart, 1983; Taasoobshirazi \& Glynn, 2009; Tuminaro \& Redish, 2007). Instead, students often use a plug-and-chug approach and get stuck (Bing \& Redish, 2007; Eichenlaub \& Redish, 2019; Kuo et al., 2013; Schuchardt, 2016). One hypothesis for students' failure to integrate mathematics and science resources is that during instruction, they are not provided with opportunities to simultaneously engage in both mathematical and scientific sensemaking of mathematical equations in science (Eichenlaub \& Redish, 2019; Schuchardt \& Schunn, 2016). Instruction that is designed to create opportunities for blended sensemaking is related to improved student quantitative problemsolving skills and conceptual understanding (Schuchardt \& Schunn, 2016). Therefore, instructors have been encouraged to create more opportunities for students to engage in blended sensemaking (Bain et al., 2018; Eichenlaub \& Redish, 2019). However, there are too few studies of instruction of mathematical equations in science to determine whether no sensemaking opportunities are provided, whether sensemaking opportunities are only provided in one dimension (science or mathematics), or whether both types of sensemaking are provided, but not integrated with one another. The failure to organize integrated mathematics and science sensemaking opportunities during instruction might explain students' tendency not to engage in blended sensemaking when problem solving (Eichenlaub \& Redish, 2019; Schuchardt, 2016).

\section{Conceptual framework}

This study describes the different sensemaking opportunities provided by four undergraduate instructors during their lessons on mathematical equations in biology. 
During instruction, an instructor can focus on different types of knowledge embodied in an equation, either separately as scientific knowledge or as mathematical knowledge, or as blended sensemaking if sensemaking from both science and mathematics dimensions are merged during the instruction (Bain et al., 2018; Bing \& Redish, 2007; Kuo et al., 2013). The sensemaking opportunities created by instructors around a mathematical equation in biology will be identified separately in the mathematics and science space using the Sci-Math Sensemaking Framework (Zhao \& Schuchardt, 2021). Then, instances where instructors provide opportunities for blending both types of sensemaking of the equation will be discussed.

The Sci-Math Sensemaking Framework was developed based on an extensive literature review of published work from both science education and mathematics education fields on sensemaking of equations (Table 1, Zhao \& Schuchardt, 2021). The Sci-Math Sensemaking Framework includes nine categories for different types of sensemaking, four in the science dimension and five in the mathematics dimension (Table 1, Zhao \& Schuchardt, 2021). Sensemaking opportunities in science include definition of variables (Sci-Label), understanding an equation as a definition of a parameter of an object or a system that cannot be directly measured (Sci-Description), understanding qualitative trends in the represented phenomenon (Sci-Pattern), and understanding the mechanism causing the phenomenon to occur (SciMechanism). Sensemaking opportunities in mathematics include application of a step-by-step algorithm (MathProcedure), knowledge of generalizable statements guiding calculation (Math-rule), understanding the implications of different arrangements of symbols and operations (Math-Structure), identification of quantitative relationships (Math-Relation), and understanding the mathematical ideas embedded in the equation (Math-Concept).

Identification of the different types of sensemaking opportunities in the science and mathematics dimensions allows for characterization of how sensemaking opportunities are organized. Co-occurrence of science mathematics sensemaking that is taught so that one type of sensemaking is used to support or explain the other (blended sensemaking) presents an integrated approach to teaching and learning in STEM (Li \& Schoenfeld, 2019). In contrast, if mathematics sensemaking and science sensemaking is provided separately in adjacent instructional segments, then instruction presents mathematics and science as separate disciplines without connections. (Li \& Schoenfeld, 2019). Distinguishing between the different approaches to organizing sensemaking, not just characterizing the types that are present, provides insight into whether instruction provides opportunities for students to make sense of connections between the two disciplines, which may inform their problem-solving.

\section{Current study}

The research goal is to identify different types of sensemaking opportunities provided by different instructors teaching the same biological phenomenon with mathematical equations. According to Yin (2017), a case study method is appropriate when the goal is to provide an indepth description of how a social phenomenon occurs. A multiple case study design was used to illustrate the

Table 1 Categories in the Sci-Math Sensemaking Framework (Zhao \& Schuchardt, 2021)

\begin{tabular}{|c|c|c|}
\hline Dimension & Category & Short definition \\
\hline \multirow[t]{4}{*}{$\begin{array}{l}\text { Science } \\
\text { sensemaking }\end{array}$} & Sci-Label & $\begin{array}{l}\text { Connects variables or operators in mathematical equations to quantifiable characteristics of objects or processes } \\
\text { in the scientific phenomenon, i.e., the definition or scientific meaning of the variable (e.g., } m=\text { mass) }\end{array}$ \\
\hline & $\begin{array}{l}\text { Sci- } \\
\text { Description }\end{array}$ & $\begin{array}{l}\text { Uses a mathematical equation to provide a quantifiable measure of a parameter of a scientific phenomenon or } \\
\text { an object within the phenomenon (e.g., equations for diversity index, the equation for density) }\end{array}$ \\
\hline & Sci-Pattern & $\begin{array}{l}\text { Emphasizes the qualitive trend or pattern among variables in the mathematical equation situated within the } \\
\text { scientific phenomenon (e.g., in the equation } F=m a \text {, acceleration is proportional to the force on an object) }\end{array}$ \\
\hline & $\begin{array}{l}\text { Sci- } \\
\text { Mechanism }\end{array}$ & $\begin{array}{l}\text { Emphasizes connections to a mechanism that explains how or why a scientific phenomenon occurs (e.g., for the } \\
\text { equation } \vec{a}=\vec{F}_{\text {net }} / m \text {, the net force distributed over mass causes the acceleration of an object in the same } \\
\text { direction) }\end{array}$ \\
\hline \multirow[t]{5}{*}{$\begin{array}{l}\text { Mathematics } \\
\text { sensemaking }\end{array}$} & $\begin{array}{l}\text { Math- } \\
\text { Procedure }\end{array}$ & Emphasizes the predetermined steps or algorithms for problem solving \\
\hline & Math-Rule & $\begin{array}{l}\text { Focuses on generalizable statements that guide calculation (e.g., the probability of two events occurring } \\
\text { simultaneously is equal to the product of the individual probabilities) }\end{array}$ \\
\hline & $\begin{array}{l}\text { Math- } \\
\text { Structure }\end{array}$ & $\begin{array}{l}\text { Focuses on the form of the equation, the numbers and arrangement of symbols and operations (e.g., } \quad+\quad \text { as } \\
\text { two components adding together) }\end{array}$ \\
\hline & $\begin{array}{l}\text { Math- } \\
\text { Relation }\end{array}$ & $\begin{array}{l}\text { Emphasizes quantitative relationships between variables in the equations (e.g., } v=9.8 \mathrm{~m} / \mathrm{s}^{2} * t+v_{0} \text { says that if } v_{0} \text { is } \\
0, v \text { will be } 9.8 \text { times bigger for every unit increase in } t\end{array}$ \\
\hline & $\begin{array}{l}\text { Math- } \\
\text { Concept }\end{array}$ & $\begin{array}{l}\text { Refers to a network of knowledge that enables explanation of the what, how and why of a mathematical idea } \\
\text { (e.g., conceptually, probability is the proportion of desired events out of all possible events) }\end{array}$ \\
\hline
\end{tabular}


range of sensemaking that can occur in science classrooms. A case was defined as all the lessons taught by one instructor that involved equations in population growth. Cases were bounded by including only instruction that included mathematical equations. Instruction covering only biological concepts without mentioning equations was excluded from the analysis. A rich description was generated for each instructor's lessons on equations after an iterative writing and revising process among the authors. Specifically, this study aims to provide in-depth understanding of the current instructional approaches to equations in science from the sensemaking perspective. The research questions guiding this study are:

1. What sensemaking opportunities about mathematical equations do instructors provide when teaching population growth?

2. How are the sensemaking opportunities about mathematical equations organized during the lesson?

\section{Methods}

\section{Participants and instructional context}

This study draws on previously collected classroom data from 41 undergraduate biology classrooms taught by 21 instructors. The purpose of the larger study was to understand the instruction of mathematical equations in undergraduate biology classes across the nation. The instructors chosen for this study were purposefully selected because they all taught the same biological phenomenon (population growth) using mathematical equations. Therefore, this study focuses on describing the different opportunities each instructor provided for sensemaking of mathematical equations when teaching the same biological topic.

Four instructors (two female and two male) were included in this study (see Table 2). They have all been teaching for more than 5 years and have doctorates in biology. Amanda and John taught an introductory biology class to biology majors in a large Midwestern university, albeit in different semesters (class size 100-150 students). Dory taught a group of 12 students in a precollege orientation experience for incoming biology majors at the same university as Amanda and John. Miguel taught an upper-level course for biology majors at a Western Hispanic serving university (class size approximately 90 students). One of the authors was also one of the instructors.

\section{Data collection and analysis}

For each instructor, the lesson was audio recorded. Slides used in the class, and worksheets designed for students were collected. For two instructors (Amanda and John), the second author made notes about the instruction while the class was being recorded. The primary data sources for the study were the transcripts and slides from the population growth lessons. Observation field notes served as a secondary data source to provide additional details about the nature of class activities and non-verbal interactions.

The data were analyzed in two steps. First, a rich description of the instruction was produced by the first author based on the transcripts and available slides and worksheets. The third author read the descriptions along with the transcripts and noted areas of disagreement which were resolved with discussion. Second, the SciMath Sensemaking Framework was used to identify the mathematical and scientific sensemaking opportunities around mathematical equations within the rich case description. Based on the rich description, sensemaking opportunities were only identified when made available to all students either through verbal statements made by instructors or by students in large group discussions and presentations or on slides presented to the class. When the sensemaking was not made explicit to all students in the class, it was not identified. The purpose is not to provide an exhaustive list of all instances of sensemaking in the rich descriptions, rather to understand how instructors set up and afford sensemaking opportunities. The same two authors and a colleague with expertise in science education discussed the identification of sensemaking opportunities, and a consensus was reached. The identified sensemaking opportunities were added to the rich description in parentheses. Patterns in the types and the order of sensemaking opportunities were identified. A cross-case analysis was performed based on comparing and contrasting the sensemaking opportunities in the four instructors' lessons. The four instructors agreed

Table 2 Participants and instructional context for each instructor

\begin{tabular}{llll}
\hline Instructor & University & Class size & Course level \\
\hline Amanda & R1 Midwestern university & $100-150$ & Introductory biology major \\
John & R1 Midwestern university & $100-150$ & Introductory biology major \\
Miguel & R2 Hispanic serving university & $\sim 90$ & Upper-level biology major \\
Dory & R1 Midwestern university & 12 & Pre-college orientation for biology majors \\
\hline
\end{tabular}

Indicates that the instructor is one of the authors 
with the presentation of their lessons as described in this manuscript.

\section{Results}

The results are first presented by individual case. The rich description of each instructor's implemented lesson on equations about population growth is presented, followed by an analysis of each case guided by the nine categories in the Sci-Math Sensemaking Framework (Table 1). A summary of the specific equations used by each instructor is provided in Table 3. Within the case descriptions, the equations are referred to by number.

\section{The description of Amanda's instruction}

Amanda spent 97 min teaching equations on population growth, $63 \mathrm{~min}$ in the first class, and $34 \mathrm{~min}$ in the second class. Amanda started her instruction in population growth by stating, "So we're going to start looking at not just life tables now, but actually have you look at the growth of populations. How is it changing over time?" She shared a life table of the population of northern water snakes (Fig. 1). After naming the variables (SciLabel), $l_{x}$ and $m_{x}$ as survivorship and fertility respectively, Amanda showed students how to calculate $R_{0}$ (Equation 1, Table 3). She presented the calculation as a series of steps, first explaining, "we multiply a survivorship to each age class by the fertility, we get net offspring produced at each age" and then, "If you take the sum of that column, $l_{x}$ times $m_{x}$, you get the net reproductive rate per generation" (Math-Procedure). Amanda concluded this example by describing $R_{0}$ (which is calculated by Equation 1) as "a population growth parameter" (Sci-Description) and explaining how to interpret the parameter, because "It $\left[R_{0}\right]$ is 0.79 , meaning each female produces 0.79 offspring, so not even reproducing themselves. So, this population is in decline." She introduced a second equation (Equation 2, Table 3) to calculate generation time for the snake population in the same

Table 3 Mathematical equations used by instructors

\begin{tabular}{|c|c|c|c|c|c|}
\hline Equation label & Equation & Amanda & John & Miguel & Dory \\
\hline Equation 1 & $R_{0}=\sum I_{x} m_{x}$ & $\checkmark$ & & & \\
\hline Equation 2 & $g=\sum x I_{x} m_{x} / R_{0}$ & $\checkmark$ & & & \\
\hline Equation 3 & $\lambda=R_{0}^{1 / g}$ & $\checkmark$ & & & \\
\hline Equation 4 & $N_{t}=N_{0} \lambda^{t}$ & $\checkmark$ & & & \\
\hline Equation 5 & $d N / d t=r N$ & $\checkmark$ & $\checkmark$ & & \\
\hline Equation 6 & $\frac{d N}{d t}=N r_{\max }\left(\frac{K-N}{K}\right)$ & $\checkmark$ & $\checkmark$ & & \\
\hline Equation 7 & $N_{t}=N_{0} 2^{n}$ & & & $\checkmark$ & $\checkmark$ \\
\hline Equation 8 & $n=3.3 \log \left(N_{t} / N_{0}\right)$ & & & $\checkmark$ & \\
\hline Equation 9 & $g=t / n$ & & & $\checkmark$ & \\
\hline Equation 10 & $k=n / t$ & & & $\checkmark$ & \\
\hline
\end{tabular}

way, first defining generation time as "the average time between the mother and the daughter's first offspring" (Sci-Description) and then working step by step to show how to calculate generation time (Math-Procedure).

Following her presentation of the steps to calculate $R_{0}$ and generation time, Amanda went over the logistics of the weekly project, which asked students to calculate population growth parameters including generation time using data tables formatted identically to the snake example. Amanda offered step-by-step instructions,

What you eventually want to calculate is $g$, the generation time there (Sci-Label) And the other thing you're going to do is to calculate current age distribution, given a stable population. So, read through the directions carefully. I carefully typed it out step by step to help you work through this. (MathProcedure).

After students worked in groups for about $30 \mathrm{~min}$, Amanda described how to estimate growth rates in the population. This presentation followed the same structure as the previous instruction with Amanda presenting Equation 3 and steps of calculation for a new variable $\lambda$ (Math-Procedure). Then Amanda presented Equation 4, the geometric growth equation, by naming each variable (Sci-Label) and then described the biological meaning of the parameter $\lambda$ (defined by Equation 3) by "You have this finite rate of increase that's greater than one, population is increasing. This last one is decreasing. If it equals one, the population is constant" (Sci-Description). Amanda then introduced the differential equations for continuous growth (Eqs. 5 and 6) by naming the equations, geometric growth equation and continuous growth equation, and then named the variable $r_{\max }$ as "the intrinsic rate of increase" (Sci-Label). At the end of the first class, she expressed her expectations to the students by saying "What I want you to know are the terms in the equations. What is $\lambda$, what is $R_{0}$, what do these terms mean? (Sci-Label) What is each equation used for?"

At the beginning of the second class, Amanda reviewed the definition of $r_{\max }$ in Equation 6 ( $\mathrm{Sci}$ Label). She showed the logistic growth equation with a new variable, carrying capacity ( $K$ in Equation 6, Table 3). Amanda defined $K$ as "how many individuals the environment can support" and said that the entire term $r_{\max }\left(1-\frac{N}{K}\right)$ is called "the realized growth rate" (Sci-Label) when resources are limited for the population. Amanda went on to explain the pattern among carrying capacity $(K)$, initial population size $(N)$, and the realized growth rate. She said, "realized 


\begin{tabular}{|c|c|c|c|c|}
\hline Age (years) & \# survivors & Survivorship: $I_{x}$ & Fertility: $m_{x}$ & $I_{x} m_{x}$ \\
\hline 0 & 1000 & 1.0000 & 0.0000 & 0.0000 \\
\hline 1 & 400 & 0.4000 & 0.0000 & 0.0000 \\
\hline 2 & 164 & 0.1640 & 0.0000 & 0.0000 \\
\hline 3 & 100 & 0.1000 & 0.0000 & 0.0000 \\
\hline 4 & 64 & 0.0640 & 5.5400 & 0.3546 \\
\hline 5 & 30.7 & 0.0307 & 6.7600 & 0.2075 \\
\hline 6 & 14.8 & 0.0148 & 7.8100 & 0.1156 \\
\hline 7 & 7.1 & 0.0071 & 8.8900 & 0.0631 \\
\hline 8 & 3.4 & 0.0034 & 9.1000 & 0.0309 \\
\hline 9 & 1.6 & 0.0016 & 9.2400 & 0.0148 \\
\hline 10 & 0 & 0.0000 & 0.0000 & 0.0000 \\
\hline
\end{tabular}
Net reproductive rate
per generation:

Fig. 1 Slide presented during Amanda's instruction. The data table of the snake population and the equation for calculating $R_{0}$ on a slide presented during instruction

growth rate is going to go down depending on how close the population is to K" (Sci-Pattern).

After her presentation of Equation 6, Amanda spent 17 min implementing an activity, presenting students with three plots for different forms of Equation 6 . Amanda asked students to identify where on the plots the population growth rate is zero, positive, and negative based on the labels on the $x$-axis and $y$-axis. After students worked in groups, Amanda asked students to share their answers and checked students' answers in the whole class discussion, focusing students' attention on the names of each variable in the equations shown on the axes (Sci-Label) and the quantitative relationship between the variables on the $x$-axis and $y$-axis as shown in the equations (Math-Relation). Amanda closed the lesson on population growth by reviewing the names of the parameters, $\lambda$ (finite rate of increase), and $R_{0}$ (reproduction rate), and two of the variables located in Eqs. 6 and 5, $R_{\max }$ (intrinsic rate of increase) and $r$ (per capita growth rate) (Sci-Label).

\section{Sensemaking opportunities presented in Amanda's lesson} Amanda introduced her students to six equations in the span of $97 \mathrm{~min}$. For the first three equations, she began with defining variables (Sci-Label) or describing the parameters (Sci-Description) and then demonstrated how to use these equations step by step (Math-Procedure). Amanda reinforced her focus on Math-Procedure sensemaking, directing students to complete the tasks for the weekly project by following her step-by-step instructions. The importance of Sci-Label sensemaking during this lesson was made explicit when Amanda, at the end of the first class, stated that she expected students to know the terms in the equations.

Amanda focused on Sci-Label and Sci-Description when teaching Eqs. 4 and 5. During instruction of Equation 6, opportunities for Sci-Pattern and Math-Relation sensemaking were provided. Amanda first presented a description of changes in population growth as they relate to changes of population size with respect to carrying capacity. This portion of the lesson provided an opportunity for Sci-Pattern sensemaking because the presentation focused on describing the qualitative relationship between aspects of the biological phenomenon represented as variables in the mathematical equation. Using the same equation, Amanda engaged students in making sense of the abstract mathematical relationship between the variables (Math-Relation) by having them examine graphs and describe how the magnitude of the variables varied with respect to one another independently of the biological phenomenon. At the end of the instruction of equations, Amanda reinforced Sci-Label.

In general, Amanda's instruction of mathematical equations often started in the science sensemaking dimension, then moved to the mathematics sensemaking space and ended in the science space (i.e., Sci-Label to Math-Procedure for Eqs. 1-3, and Sci-Pattern to MathRelation for Equation 6). Science sensemaking was separated from the sensemaking of mathematics.

\section{The description of John's instruction}

John's instruction of the equations on population growth totaled $15 \mathrm{~min}$. John started the instruction of 
mathematical equations on population growth by saying, "Related to the [population] density is this idea of growth rate, which is really what we're going to be talking about." John used the growth of a fish population as an example for the exponential growth of populations, then he used an analogy from a nonscientific context, an interest-bearing bank account to focus on the mathematical relationship in exponential growth (Math-Relation). He said, "you put money into a savings account then you expect that to grow. Given some parameters about how much money you got, your principal, and the interest rate, you can predict over time how that money is going to grow." John presented a slide which showed the step-by-step procedures for calculating the increase in money between years. Using this slide, he explained the mathematical relationship among these variables with a step-by-step calculation (Math-Relation/Math-

Procedure),

So, what that means is if you put a thousand dollars into that account, $5 \%$ rate means, on average each one of those thousand dollars is contributing a nickel to the growth of that, of your money. Right. That's what that interest rate means. So, after one year, you can predict how much money you're going to have. You're going to have a thousand fifty dollars. So, your money is growing. Let that money sit more. What you see is at year 2 , you start with a thousand fifty dollars. That's how much you have in the year 1 . You let it sit there. It continues to grow. And so, between year 1 and year 2, you add fiftytwo dollars and fifty cents. How much do you add the first year? Fifty. Right? And so, we do this for another year. What we see is between year 2 and year 3, you add fifty-five dollars and twelve cents.

John then related the quantitative relationship among the principal and interest rate and the yearly growth of money to the mathematical relationship in the population growth phenomenon and stated, "money growing is really no different than population growth that we start out with a starting population size analogous to our principal and it's going to grow because each individual on average can contribute some average amount to that" (Math-Relation). After addressing the similarity in the mathematical relationship of exponential growth between money growing and population growth, John introduced Equation 5 with an emphasis on the ever-increasing rate of population growth. He provided definitions for the variables in Equation 5, "the $\mathrm{N}$ is their population size and the $r$ value is the intrinsic rate for the population" (Sci-Label).
After John presented an explanation of the biological factors that can limit population growth without referring to equations, he introduced the logistic population growth equation (Equation 6, Table 3). He defined the variable $\mathrm{K}$ as carrying capacity, "the equilibrium population size for a habitat" and labeled $\frac{K-N}{K}$ as "the dampening term" (Sci-Label). He then described the numerical relationships among mathematical variables in this term, stating that if " $N$ is small relative to the $K$, this entire term becomes a big number minus a small number divided by a big number" (Math-Relation). Next, he situated the equation in the biological phenomenon of population growth, presenting the relationship among the biological meaning of these variables, "which says populations are essentially going to grow exponentially with population size that are far away from the carrying capacity" (Sci-Pattern). John followed up by presenting the patterns for when the population size is close to $K$, first introducing the mathematical relationship among the variables (Math-Relation) and then situating the relationship in the biological phenomenon of population growth (Sci-Pattern).

At the end of the lesson on population growth, John directed students to begin working on their weekly project which presented Eqs. 1, 2, and 4 that were not discussed in class.

\section{Sensemaking opportunities presented in John's lesson}

John presented two equations (Eqs. 5 and 6) during the 15-min lecture. During the analogy of exponential growth in a non-biological context, John used MathProcedure by presenting a step-by-step procedure for calculating the growth in principal to support MathRelation sensemaking in the context of money growth. He reinforced the mathematical relationships between principal, interest rate and the increase in money, Math-Relation. After establishing the mathematical procedures and presenting the similarity of the relationship in money growth to the relationship in population growth represented by Equation 5, John provided biological definitions for each variable in Equation 5, Sci-Label.

During instruction of Equation 6, John began with SciLabel, naming the variables and terms. He continued by creating sensemaking opportunities of Math-Relation closely followed by Sci-Pattern. Because the initial focus is on the quantitative relationship between variables in the mathematical equation without referring to the biological context, the first sensemaking opportunity is considered Math-Relation. Having established the relevant mathematical relationship, John described the qualitative relationship between the biological phenomena represented in the equation, Sci-Pattern. 
John's instructional pattern changed with each of the equations included during the class. With Equation 5, he started in the mathematics sensemaking space, then moved to and ended in the science sensemaking space (Math-Relation and Math-Procedure to Sci-Label). Whereas with Equation 6, he started in the science sensemaking space, moved to mathematics sensemaking space, and ended in the science sensemaking space (Sci-Label to Math-Relation to Sci-Pattern). Math-Relation and Math-Procedure occurred simultaneously in the mathematics sensemaking space, while science sensemaking was always separated from the sensemaking of mathematics.

\section{The description of Miguel's instruction}

Miguel spent 43 min teaching equations on population growth. He started his instruction of population growth in bacteria by directing students to work on a "thought exercise" (Fig. 2) which asked students to draw a picture of population growth and then represent that growth mathematically. Students worked by themselves first, and then worked in small groups.

After 6 min of group work, Miguel interrupted to pose questions to the entire class, focusing their attention on the relationship between the number of progeny and the number of generations by stating,

So now, class, look at the numbers that you put there. How is that number of cells related to the generation that you're looking at? So, look, how many cells are in the first generation? How many cells are in the second generation? How many cells in the fourth generation? (MathRelation)

After students worked for four additional minutes, Miguel had each group write the equations they had developed on their whiteboards and started his presentation to the whole class. Miguel drew the number of cells after multiple cell divisions and explained his drawing. On the drawing, he labeled the number of generations and highlighted the relationship between the number of cells and the number of generations by stating,

OK, we have one cell. That cell is going to divide and have two progeny (Sci-Mechanism). Of course, this cell is going to divide and also have two progeny as well as this one [Miguel continues drawing cells and progeny]....Which gives us the numbers that you came up. Before there was any division, there was only one cell. After the first generation, now there are two cells. After the second generation, now we have four cells. Eight cells after the third and 16 cells after the fourth. So put the generation here. Generation 2 to the 1 , as you guys concluded very nicely. 2 to the 2,2 to the 3,2 to the 4 . That is the sequential relationship (Math-Relation).

Based on the quantitative relationship, Miguel presented the mathematical expression that he expected students to come up with, "2 to the $n$ " (Equation 7, Table 3). He asked the whole class after presenting the equation, "the cells will be two to the $n$ where $n$ is the

\section{Thought exercise 1}

- Here is one bacterial cell. - 1 cell duplicates into 2 cells

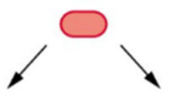

- By yourself first, illustrate the progeny this cell would have after 1,2, and 3 cell divisions on the worksheet provided. Fill up the number of progeny (daughter cells).

- Compare your illustration and numbers with your group.

- What is the relationship between the numbers of cells after each cell division?

- How would you express the sequence of numbers of daughter cells mathematically?

Fig. 2 Slide presented in Miguel's instruction. Directions for building mathematical equation of the population growth of bacteria presented on a slide during instruction 
number of generations or cell divisions. (Sci-Label) Right? OK. Now, I have a quick question for you. Do we always start with one cell? How would you accommodate now if you don't start with one cell? (Sci-Pattern) What would you do?" Miguel followed up on a student's answer by saying, "Everybody heard Emily? Then you will know. Multiply it by the number of cells that you had at the beginning." (Math-Structure) Miguel added the variable $N_{0}$, resulting in the canonical equation, $N_{t}=$ $N_{0} 2^{n}$, which he defined as "the number of cells at time $T$ is going to be equal to the number of cells initially $N_{0}$ times two to the $n$, where little $n$ is the number of generations" (Sci-Label).

Miguel switched to calculations using this canonical equation by asking the whole class how the equation could be manipulated to solve for $n$. He said, "That's an equation that you guys came up with. We have an exponent. You remember what needs to happen if you want to calculate little $n$ when you have a number to the $n$ power, what will you need to do?" After one student volunteered the answer, Miguel showed the class the steps of manipulating the canonical equation of population growth of bacteria to get the equation for calculating the number of generations (Math-Procedure, Equation 8, Table 3). He brought up some mathematical rules when presenting the procedures of manipulating the equation. For example, he said, "From any kind of addition, you can move this value of $\log N_{0}$ to the other side by subtracting it" (Math-Rule).

After presenting the equation for calculating the number of generations, Miguel asked students to solve an application question, calculating the final population size for bacteria (Application question 1, Table 4). After students briefly worked in groups, Miguel asked the students to share their answers, and confirmed with students the correct answer. Miguel concluded with his expectation for students to plug numbers into the equation, saying "All right, everybody gets the same number. Good job! So, you know, you're getting used to getting into the equation, how to plug the numbers in and use it" (Math-Procedure).

Before moving on to application question 2, Miguel introduced a new population growth parameter, generation time, described by Equation 9 (Table 3) (Sci-Description) and then asked students to solve application question 2. Application question 2 (Table 4) asked students to calculate the final population size for bacteria that had different generation times. Students worked in small groups to solve application question 2 .

After students had worked on application question 2 in small groups for $9 \mathrm{~min}$, Miguel moved on to present a new variable described as "How many generations can we get in an amount of time" (Equation 10, Table 3, SciDescription). He presented this variable by focusing on the structure of the equation by stating "It's the inverse of the generation time. Generation time is the time divided by the number of generations. The specific growth rate $(k)$ is the opposite, the number of generations divided by a particular unit of time" (Math-Structure). Then he presented the steps of calculating the growth rate, stating,

So, you can calculate this easily because you know that you have one generation. One generation happens in how much time? [One student answered] Six hours since the growth rate is the number of the time divided by the number of generations. That is six divided by one, which is six. (Math-Procedure)

Miguel ended the class after he directed students to calculate the growth rate $(k)$ for application question 3 (Table 4).

\section{Sensemaking opportunities presented in Miguel's lesson}

Miguel introduced four equations (Equations 7-10) during the $43 \mathrm{~min}$ of class on population growth. Miguel began with a focus on Math-Relation by engaging students in developing an equation to show the relationship among numbers of cells for different numbers of generations. During his presentation to the whole class after students finished their work, Miguel introduced the mechanism of cell division to explain how the mathematical relationships were generated (Sci-Mechanism/Math-Relation). A suggestion that modifying the initial starting number of cells might lead to changes briefly touched on Sci-Pattern which led to the incorporation of this variable into the equation using multiplication (Math-Structure). To wrap up this portion of the lesson, Miguel shifted to Sci-Label sensemaking when he presented the canonical form of the equation and defined the variables.

Table 4 The application questions presented to students during Miguel's instruction

\begin{tabular}{|c|c|}
\hline ID & Content \\
\hline 1 & $\begin{array}{l}\text { You made jam with } 0.5 \mathrm{lb} \text { of blueberries. These berries were contaminated with } 500 \text { endospores of Clostridium botulinum. After } 100 \text { cell } \\
\text { divisions, how many bacteria would you have in your jam? }\end{array}$ \\
\hline 2 & $\begin{array}{l}\text { Suppose } 1000 \text { bacteria are inoculated in a tube containing a minimal salts medium, where they double once an hour, and } 10 \text { bacteria are } \\
\text { inoculated into a rich medium, where they double every } 20 \text { min. Which tube will have more bacteria after } 2 \mathrm{~h} \text { ? After } 4 \mathrm{~h} \text { ? }\end{array}$ \\
\hline 3 & For Application question 2, determine and compare the specific growth rate $(k)$ for these two cultures. \\
\hline
\end{tabular}


In showing students how to transform Equation 7 into Equation 8, Miguel focused on the steps for manipulating the equation including explicit discussion of relevant mathematical rules, thus providing opportunities for Math-Rule to support Math-Procedure. With Equations 9 and 10, Miguel explicitly stated that these were factors or parameters that affect population growth and that they were calculated using an equation (Sci-Description). When introducing Equation 10, Miguel provided opportunities for Math-Structure and Math-Procedure when he noted that the structure of Equations 9 and 10 were the inverse of each other and demonstrated the steps for calculation using Equation 10.

The majority of Miguel's instruction was spent in the mathematical sensemaking space (Math-Relation, MathRule, Math-Procedure). During the first portion of the lesson, science sensemaking and mathematical sensemaking co-occurred (Sci-Mechanism/Math-Relation), and Math-Rule co-occurred with Math-Procedure in the same mathematics sensemaking space, but during the second half of the lesson, science sensemaking and mathematical sensemaking were separated.

\section{The description of Dory's instruction}

Dory's instruction of mathematical equations in population growth lasted for $111 \mathrm{~min}$, with $35 \mathrm{~min}$ of instruction for the first part of the lesson, and $76 \mathrm{~min}$ for the second part of the lesson. Dory started with an equation building activity where students were asked to represent mathematically how a bacteria colony forms from a single bacterium (Fig. 3). Students worked individually for $3 \mathrm{~min}$, then Dory directed them to work in pairs by saying,
Go ahead and put [your initial ideas] on the chart paper. If you're using symbols or numbers, say what the symbols or numbers mean (Sci-Label). For example, $X$ is just $X$, but if the $X$ means how often the bacteria divide, we need to know that, or how many bacteria are produced. Because $X^{\prime} s$ and $Y^{\prime}$ s don't help us if they don't communicate that...And I'm asking you to do both a picture, a math expression, and a verbal description. And put your names on it, and we're going to post them up and share them.

While students discussed with their partner and drew on their chart paper, Dory moved around to interact with different groups.

After $15 \mathrm{~min}$, Dory guided students to put the chart paper on the wall and students took turns presenting their work. Dory asked students to present their equation and to explain the meaning of the symbols or numbers they had in their equation (Sci-Label). During the group discussion after each group's presentation, Dory posed questions on how their equations connected to the biology of the phenomenon of population growth, and she encouraged the other students to ask questions. For example, after one group presented their equation and the meaning of each variable in their equation, Dory asked them to explain the difference in their equation compared to the equation presented earlier, $=2^{x}$. Students explained to the whole class that they used $x / n$ as the exponent rather than $x$ (Math-Structure) because they tried to represent how long an individual cell takes to divide by using $n$ (Sci-Mechanism). A student brought up the idea of how to account in the equation for different factors that might affect cell division (SciMechanism) and the class discussed how this would

Activity 3. Developing a model of population growth.

1) Draw picture illustrating your ideas of how a bacteria colony on the plate could form from a single bacterium.

Share your ideas with your partner(s).

2) Develop a mathematical expression which would allow someone to calculate the number of bacteria present at a particular time point.

Share your ideas with your partner.

3a) Put your consensus picture, mathematical expression and short written description on a piece of chart paper for class discussion.

3b) Given the class discussion, what did you need to modify about your mathematical expression and why? How does this affect your thinking about the phenomenon?

Fig. 3 Dory's instructions for building a mathematical equation on the worksheet provided to students 
affect the $x / n$ term (Math-Structure). Dory affirmed that "there are things that just basically stop [cells] dividing....So I think [this equation] does allow you to do that because if the $\mathrm{n}$ was really long, really large, then you, basically, would not get to this" (Sci-Mechanism, MathStructure).

The last group that presented included a variable representing the initial number of bacteria (equivalent to $N_{0}$ in Equation 7). The presenters explained their rationale for including this variable and a multiplication function (Math-Structure) by connecting to the biological idea that the population does not always start at one and providing a biological pattern which would necessitate multiplication (Sci-Pattern). Dory affirmed the students' ideas and shared additional scenarios when the initial population size needs to be included. She prompted students to consider the effect of those changes on the predicted population size (Sci-Pattern) and connected to the variable under discussion by saying "So, $x$ in this case is the number of bacteria that you start your culture with" (Sci-Label).

After all groups had presented, Dory started writing on her chart paper (Fig. 4) and said, "So we are going to put together maybe an amalgamation of equations." She wrote the equation as number of bacteria $=N_{0} \times 2^{t} / F$, and labeled each variable by stating, " $t$ equals time elapsed, and $F$ equals the time for binary fission to occur. But sometimes we call that generation time" (Sci-

$$
\begin{aligned}
& \text { \# bacteria }= \\
& M_{0} \times 2^{2} / f \\
& \left.N_{0}=\text { bacteia start } \omega\right) \\
& 2=\text { each bacteria splits } \\
& t=\text { time elapsed } \\
& F=\text { binary fission time }
\end{aligned}
$$

Fig. 4 Artifact from Dory's instruction. The equation presented to students at the end of the activity on building a mathematical equation for growth of a single type of bacteria in the shaken culture (Note: Dory changed the exponent $x$ to $t$ to make the connection to the biological phenomenon more explicit)
Label). Based on this equation, she asked students "Why is that two there? What does it mean?" After a student volunteered that it was a constant, Dory prompted, "It's a constant, but it's a two. Why is it two and not four?" Dory confirmed the next student's response, "Yeah. It's the number of bacteria produced by each bacterium" (Sci-Mechanism).

Dory started the second part of the lesson by stating that she had heard students say that the equation they had developed was not a good representation of the population growth in a different condition, where two types of bacteria grew in the same space. She asked students to modify their equation to fit the new condition. Students worked independently for $2 \mathrm{~min}$ and then in pairs for $37 \mathrm{~min}$, writing their new equations on poster paper. After the small group work, Dory asked students to look at other groups' posters and to share their posters as they did previously. During the whole class discussions, multiple ideas surfaced about the connections of the equation to the biological phenomenon of population growth and how the mathematical structure could be used to depict ideas and observations about the phenomenon. For example, one group presented their equation and explained that they noticed a pattern in the data that Smooth bacteria grew slower than the Wrinkly bacteria (Sci-Pattern) and that they used multiplication (Math-Structure) to represent this pattern. The whole class discussed which bacteria grew faster (SciPattern) and how to match the multiplication (MathStructure) correctly to the pattern. Dory summarized students' conversations about using the mathematical structure of multiplication to indicate that it took the Smooth bacteria a longer time to reproduce than the Wrinkly bacteria. "Yes. You're saying that it takes a longer amount of time for the Smooth to reproduce, and therefore you have to multiply it by two, compared to the Wrinkly to indicate that" (Sci-Pattern and MathStructure). In another example, the student group presented the difference in growth rates of these types of bacteria by adding a subtraction. Guided by Dory's questions, such as "what are you proposing biologically happens when you do a subtraction" (Math-Structure), this group explained that during population growth, Smooth and Wrinkly bacteria competed for resources, and Smooth bacteria were being killed by the Wrinkly as Wrinkly were better (Sci-Mechanism), thus a subtraction was used to better represent the population growth phenomenon (Math-Structure).

Dory also pointed out to the whole class that equations had boundaries and limitations (Math-Concept). After one group presented their equation that considered the time when the Wrinkly Spreader started reproduction and the idea of carrying capacity, Dory stated, "You actually put some boundaries on this 
equation...T can't be less than 12 , otherwise we get a negative time", and "the other limitation you put it on, this only applies in certain circumstances. Good. It's nice to have limitations on equations" (Math-Concept). Dory wrapped up this activity by pointing to students that there was not a right equation and the choice of which equation to use depended on "the ideas you're trying to express".

\section{Sensemaking opportunities presented in Dory's lessons}

Dory engaged students in building two equations to represent population growth in $111 \mathrm{~min}$. Both parts of the lesson followed the same format, students worked on building equations in small groups writing their ideas on poster paper. Then students presented their equation to the class.

During the presentation of equation ideas in the first whole class discussion, Dory consistently asked students to explain how the variables or the mathematical operations in their equation were connected to aspects of the biological phenomenon. In response to these prompts, students discussed how structural aspects of the equation such as including a divisor in the exponent or using multiplication (Math-Structure) related to the biological mechanism of cell division that causes population growth (Sci-Mechanism). At the end of the discussion, Dory synthesized students' ideas into a single equation and labeled the variables (Sci-Label). She paused at one point in the labeling to ask students to relate the constant in the equation to the biological mechanism of cell division (Sci-Mechanism).

During the second part of the lesson, the focus in the discussion was on using equations to describe the differences in population growth in two kinds of bacteria. During this discussion, ideas about patterns of growth (Wrinkly bacteria grew slower than Smooth bacteria) (Sci-Pattern) surfaced along with biological mechanisms to explain this difference in growth (Sci-Mechanism). Students described how these ideas were represented in their equation by functions such as multiplication or subtraction (Math-Structure). The first set of presenters spontaneously explained how the pattern of growth was described by multiplication in their equation. Dory prompted the second set of presenters to explain how subtraction was used to indicate that one bacteria type grew slower than another, eliciting a description of how subtraction represented the biological mechanism of competition. During this discussion, in Dory's summaries of students' comments, she drew attention to how the choice of mathematical functions connected to students' ideas about the biological phenomenon, connecting Math-Structure with Sci-Pattern or Sci-Mechanism. Toward the end of the discussion, Dory highlighted the
Math-Concept of limits of equations that one student group had depicted on their poster.

Dory's lesson started with providing the Sci-Label space for all students. Dory engaged students in using science sensemaking (Sci-Pattern or Sci-Mechanism) to support their Math-Structure during the sharing of ideas in whole class discussions. Dory often wrapped up each group's presentation and discussion with summary statements that integrated the mathematical sensemaking and science sensemaking spaces.

\section{Discussion}

A cross-case analysis revealed that the instructors all covered mathematical equations that represented aspects of the same biological phenomenon, population growth. However, the sensemaking opportunities that were provided with respect to these equations differed from instructor to instructor (Table 5) even though all were teaching the same biological phenomenon. The organization of the types of sensemaking also varied in interesting ways. After a brief description of the different types of sensemaking presented by different instructors, the organization of sensemaking opportunities will be discussed in greater depth.

\section{The types of sensemaking provided by the four instructors differ}

All instructors provide opportunities for multiple types of sensemaking of equations in the lessons (Table 5). Even though all instructors are teaching equations associated with population growth, there are differences in the number of types of sensemaking and what sensemaking opportunities instructors chose to provide in their classes. Amanda and John provide the same subset of sensemaking opportunities with the exception that Amanda also includes Sci-Description. Dory's instruction is the most different from the others, with Sci-Mechanism, MathStructure, and Math-Concept present in Dory's class but not in Amanda or John's. The Math-Procedure sensemaking that is present in Amanda and John's class is absent from Dory's class. Miguel is a combination of these two types of instructional approaches, with eight types of sensemaking that are present in the other three instructors' classes. The one type of sensemaking that is missing is MathConcept, and Miguel is the only one that has MathRule. Describing the types of sensemaking included in a lesson has the potential to make instructors aware of what is included and what is excluded so that they can determine if the instructional opportunities provided for sensemaking match their learning objectives for students. 
Table 5 Sensemaking opportunities during four instructors' lessons on equations in population growth

\begin{tabular}{|c|c|c|c|c|c|}
\hline Sensemaking dimension & Sensemaking category & Amanda & John & Miguel & Dory \\
\hline \multirow[t]{4}{*}{ Science sensemaking } & Sci-Label & $\checkmark$ & $\checkmark$ & $\checkmark$ & $\checkmark$ \\
\hline & Sci-Description & $\checkmark$ & & $\checkmark$ & \\
\hline & Sci-Pattern & $\checkmark$ & $\checkmark$ & $\checkmark$ & $\checkmark$ \\
\hline & Sci-Mechanism & & & $\checkmark$ & $\checkmark$ \\
\hline \multirow[t]{5}{*}{ Mathematics sensemaking } & Math-Procedure & $\checkmark$ & $\checkmark$ & $\checkmark$ & \\
\hline & Math-Rule & & & $\checkmark$ & \\
\hline & Math-Structure & & & $\checkmark$ & $\checkmark$ \\
\hline & Math-Relation & $\checkmark$ & $\checkmark$ & $\checkmark$ & \\
\hline & Math-Concept & & & & $\checkmark$ \\
\hline
\end{tabular}

By providing opportunities for multiple types of sensemaking, instructors expose students to different resources that students can use to develop their understanding of equations and the scientific phenomenon. However, it may be possible to try to include too much in a single lesson leading to superficial coverage of some types of sensemaking and impeding development of in-depth understanding. Miguel who covers eight types of sensemaking only touches on Sci-Mechanism briefly, while Dory returns to this type of sensemaking repeatedly through the lesson. It is likely that a balance is needed between in-depth coverage and presentation of multiple types of sensemaking. Future studies are needed to characterize the affordances and constraints for students' sensemaking and problem solving of these two approaches to covering types of sensemaking of mathematical equations in science instruction.

\section{Amanda (97 minutes)}

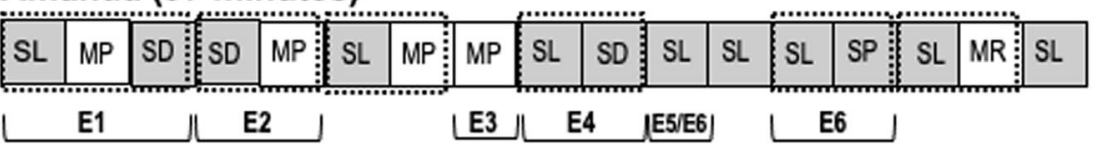

John (15 minutes)

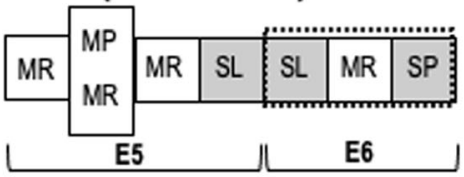

Miguel (43 minutes)

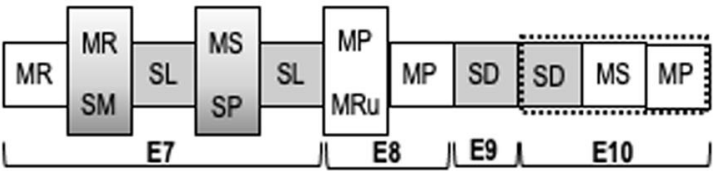

Dory (111 minutes)
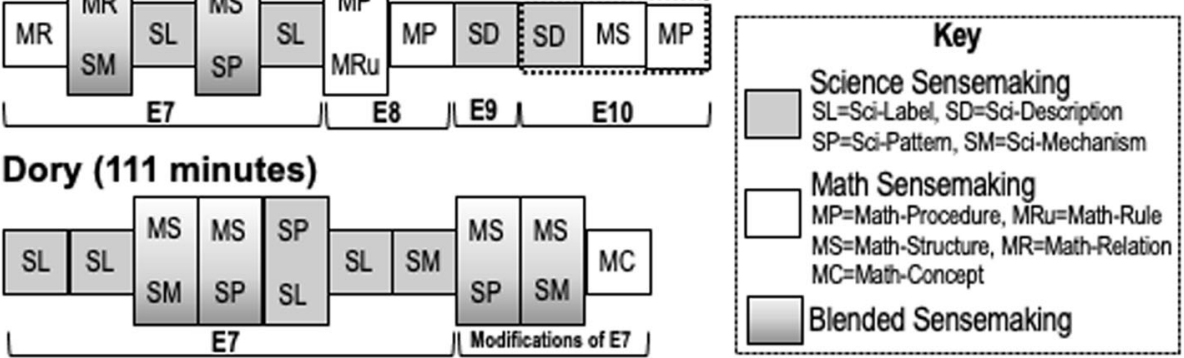

Fig. 5 The organization of sensemaking opportunities identified during each instructor's lesson on equations about population growth. The types of sensemaking opportunities are presented in sequential order. Mathematics sensemaking is placed in a white box, and science sensemaking is placed in a gray box. Sensemaking opportunities that co-occurred are placed in a single box. A gradient background indicates a co-occurrence of sensemaking from both mathematics and science dimensions. Each sensemaking type corresponds to a single activity except where a dotted box indicates that different types of sensemaking opportunities occur in the same activity. $E=$ Equation. Amanda has several periods of sensemaking that are not associated with a specific equation. During these times she was summarizing the lesson, either as students transitioned to a new activity or to wrap up the class. Instructional time is not represented in the figure 


\section{Sensemaking opportunities were organized differently} Instructors presented the types of sensemaking opportunities in different sequences (Fig. 5). For example, John and Miguel started with sensemaking in the mathematics dimension and then moved on to sensemaking in the science dimension while Amanda and Dory started with sensemaking in the science dimension and progressed to sensemaking in the mathematics dimension. One of the key differences between instructors was whether different types of sensemaking occurred within the same activity and whether or not those different types of sensemaking were used to support one another. (An activity is defined as a classroom-based episode whose purpose is to focus students' attention on a particular equation, scientific or mathematical idea, or a practice.) These differences in the organization of sensemaking have implications for whether or not students were provided with the opportunity to engage in blended sensemaking synergistically to achieve a novel outcome (Fauconnier \& Turner, 1998). Three types of co-occurrence of sensemaking within the same activity were observed, Blended (which has been described by other researchers during student problem-solving) (Bain et al., 2018; Bing \& Redish, 2007; Kuo et al., 2013), and two novel types, coordinated and adjacent. These three different ways of organizing sensemaking during instruction and potential implications for students' sensemaking will be described in more detail below.

\section{Blended sensemaking}

Blended sensemaking has been used to analyze students' problem-solving process (Bain et al., 2018; Bing \& Redish, 2007, 2008; Eichenlaub \& Redish, 2019; Kuo et al., 2013). This study provides evidence for blended sensemaking during instruction. Miguel and Dory both have instances where science sensemaking and mathematics sensemaking co-occur (gradient boxes in Fig. 5). Moreover, in these instances, one type of sensemaking is used to support or explain the other type of sensemaking. This is the blended sensemaking that Bain et al. (2018) refer to as high-quality sensemaking in students' problem solving. For example, Dory uses mathematics sensemaking of the equation to support science sensemaking of the equation as she prompts students to reason about how the mathematical structures depict the scientific ideas. Miguel also has students engage in blended sensemaking when he references the scientific mechanism for population growth (cell division) to explain the mathematical exponent function in the equation.

While Dory spends a considerable portion of the whole-class discussion on blended sensemaking, Miguel's references to blended sensemaking tend to be brief, occupying no more than a few minutes. By providing blended sensemaking opportunities to students, these instructors gave students the opportunity to grapple with connections between the mathematical equation and the scientific aspects of the biological phenomenon. Thus, students were given the opportunity to move beyond the idea of mathematics and science as fragmented and disconnected disciplines (Li \& Schoenfeld, 2019). Students' struggles with solving quantitative problems in science has been attributed to students isolating their scientific knowledge from the calculation process (Eichenlaub \& Redish, 2019). The few students who spontaneously engage in blended sensemaking during quantitative problem-solving experience greater success (Bain et al., 2018; Eichenlaub \& Redish, 2019; Kuo et al., 2013; Schuchardt, 2016). Providing explicit connections between mathematics and science sensemaking during instruction may allow more students to develop blended sensemaking and thus have improved facility with solving novel and more complex problems (Schuchardt, 2016; Schuchardt \& Schunn, 2016).

\section{Coordinated sensemaking}

Sensemaking from the same dimension co-occurs in John, Miguel, and Dory's lessons (Fig. 5). Because the sensemaking involves coordination of two types of sensemaking within the same dimension, we refer to this as "coordinated sensemaking." In Miguel's lesson, two types of mathematical sensemaking (Math-Procedure and Math-Rule) co-occur and one is used to support the other one. Miguel cues the mathematical rules to explain the steps of manipulating the equation. John presents steps of calculation (Math-Procedure) to support the understanding of the mathematical relationship of exponential growth (Math-Relation). In contrast to John and Miguel, Dory provided an opportunity for coordinating two types of sensemaking within the science dimension. She asked students to consider the changes in population growth that would results from changing the initial population size (Sci-Pattern) and based on their answers suggested that in the equation, a specific variable would be the initial population size (Sci-Label). This coordinated sensemaking within the science dimension may serve to make the labels of the variables more meaningful for students, and thus more memorable. Coordinated sensemaking differs from the blended sensemaking that has been described in the literature of making sense of equations because connections between types of sensemaking is occuring within one dimension (mathematics or science) instead of across two dimensions (e.g., Bain et al., 2018; Bing \& Redish, 2007).

Coordinated sensemaking shares similarities with the definitions of sensemaking in mathematics which focus on generating coherence within the discipline ( $\mathrm{Li} \&$ Schoenfeld, 2019). Instruction that connects different 
aspects of mathematical ideas can develop students' mathematical thinking, and foster students' beliefs that mathematical ideas are coherent and connected (Li \& Schoenfeld, 2019). Future research needs to be done to determine if coordinated sensemaking within the mathematics dimension supports students' understanding of the mathematics behind an equation and whether that impacts problem-solving. Providing opportunities for students to make connections between types of sensemaking within the science dimension may help students generate a better conceptual understanding of the biological phenomenon. This pattern of organization of sensemaking has not been identified until now. Therefore, studies exploring the effect of providing coordinated versus blended sensemaking during instruction have not yet been performed, even with curriculum that might prompt instructors to include both types of sensemaking opportunities (Schuchardt \& Schunn, 2016).

\section{Adjacent sensemaking}

All instructors, except Dory, have instructional episodes where different types of sensemaking, either within the same dimension or across dimensions, are presented sequentially within the same activity but are not explicitly connected to one another. We are labeling these instances as "adjacent sensemaking." One example of adjacent sensemaking across dimensions occurs when Amanda and Miguel both connect the variables in the equations to quantifiable characteristics in the scientific phenomenon (Sci-Label), and then immediately show the steps of how to solve the equations to calculate an answer (Math-Procedure). However, the Sci-Label is not used to explain or support the way the mathematical procedures are performed. This type of instruction seems to capture an often-described process for instruction of equations in science which focuses on learning the terminology and doing calculations (Hansson, Hansson, Juter, \& Redfors, 2015). In another example, John presents the mathematical relationships between variables in a mathematical equation (Math-Relation), then situates the equation in biology and explains how one factor represented by the equation, carrying capacity, affects population growth (Sci-Pattern). He does not discuss, or provide opportunities for students to discuss, how the pattern in population growth is related to the quantitative relationship as represented by the equation.

It is important to distinguish adjacent sensemaking from blended sensemaking. The proximity of mathematical and science sensemaking within a lesson using adjacent sensemaking gives students the opportunity to independently make connections across the dimensions. However, because the connection is not made explicit, many students might not engage in blending across the mathematics and science sensemaking dimensions. In
STEM education, teaching disciplines side-by-side within the same course is sometimes labeled (incorrectly) as integrated STEM. One example is when mathematics is used as a tool to perform a calculation after learning about the scientific phenomenon (Schuchardt, 2016). We would label this type of STEM instruction as adjacent sensemaking to distinguish it from blended sensemaking which features the use of one discipline to support or explain the other in an integrated manner. Failing to make this distinction may cause instructors to inaccurately assess the opportunities they are providing for students to develop an integrated, or blended, understanding of the mathematics and science. If future research reveals that adjacent sensemaking occurs more commonly than blended sensemaking in instruction of equations in science classes, this may explain why very few students use blended sensemaking when solving problems (Bain et al., 2018; Bing \& Redish, 2009).

\section{Limitations and future directions}

The intent of this study is to determine whether the types of sensemaking opportunities and the ways in which they are organized differ when instructors are teaching mathematical equations in the same biological phenomenon. Therefore, students' sensemaking was not characterized. The finding that the types of sensemaking and the ways in which they are organized in instruction differs between instructors supports the need for future studies on the effect of these differences on student sensemaking. The characterization of three different ways of organizing sensemaking during instruction permits informed design of future observational and quasiexperimental studies on the impact of instruction on student sensemaking.

We note that the pedagogical strategies chosen by the four instructors do differ. The different pedagogical strategies used by the instructors were not discussed because the focus of this paper was on identifying sensemaking opportunities during instruction, Future analyses with a larger sample of teachers will examine these strategies and the co-occurrence with sensemaking to determine if different pedagogical strategies are associated with the availability of different sensemaking opportunities for students.

\section{Conclusions}

By showing that instances of sensemaking can be identified using the Sci-Math Sensemaking Framework and by providing new ways of describing the organization of sensemaking opportunities, this study offers a new and valuable way to explore the nuances of sensemaking in enacted lessons of equations in science. In this study, four instructors provide different types of sensemaking opportunities in their classes even when teaching 
equations related to the same biological phenomenon. By emphasizing different sensemaking aspects of the equations, instructors make available different resources to students that have the potential to affect students' science and mathematics knowledge. This study also identifies different ways instructors organize the different sensemaking opportunities, as distinct events contained within separate activities or as co-occurring events within the same activity. In addition to the previously described blended sensemaking (Bain et al., 2018; Bing \& Redish, 2007), this study identified two other types of co-occurrence of sensemaking, adjacent and coordinated. Coordinated and blended sensemaking makes explicit connections between two types of sensemaking where one type of sensemaking is used to support or explain another type of sensemaking. However, adjacent sensemaking events are not explicitly connected. Explicitly addressing the links between different type of knowledge embodied in equations makes these connections available to all students. Based on prior work, the ability to move back and forth between connected sensemaking resources has the potential to improve students' ability to solve more complex and novel quantitative problems in science (Eichenlaub \& Redish, 2019; Kuo et al., 2013; Schuchardt \& Schunn, 2016). These findings can be used to inform future research on the effect on students' quantitative problemsolving of instruction that presents adjacent, coordinated, and blended sensemaking.

\section{Abbreviation}

STEM: Science, Technology, Engineering and Mathematics

\section{Acknowledgements}

We are thankful for the participants who opened their classroom to us. We would like to thank the Schuchardt/Warfa research group in providing feedback and suggestions on the work. We appreciate Professor Gillian Roehrig's constructive feedback during the writing process.

\section{Authors' contributions}

The first author performed data analysis and was the primary writer of the manuscript. The second author collected the data, participated in early discussions and revised the manuscript. The third author monitored the project, participated in data analysis, and co-wrote the manuscript. All authors read the final manuscript.

\section{Funding}

This study was funded by start-up funds awarded to the third author by the University of Minnesota. The funding body had no role in the design of the study and collection, analysis, and interpretation of data and in writing the manuscript.

\section{Availability of data and materials}

The datasets used and/or analyzed during the current study are available from the corresponding author on reasonable request.

\section{Competing interests}

The authors declare that they have no competing interests.

\section{Author details}

'School of Teacher Education, Nanjing Normal University, No.1 Wenyuan Road Qixia District, Nanjing, Jiangsu 210046, People's Republic of China.
${ }^{2}$ Department of Biology Teaching and Learning, College of Biological Sciences, University of Minnesota-Twin Cities, 5-220 Moos Tower, 515 Delaware Street, SE, Minneapolis, MN 55455, USA. ${ }^{3}$ Department of Biology Teaching and Learning, College of Biological Sciences, University of Minnesota-Twin Cities, 5-210H Moos Tower, 515 Delaware Street, SE, Minneapolis, MN 55455, USA.

Received: 25 August 2020 Accepted: 16 February 2021

Published online: 06 April 2021

\section{References}

American Association for the Advancement of Science (AAAS) (2011). Vision and change in undergraduate biology education: a call to action. Washington, DC: AAAS.

Bain, K., Rodriguez, J. M. G., Moon, A., \& Towns, M. H. (2018). The characterization of cognitive processes involved in chemical kinetics using a blended processing framework. Chemistry Education Research and Practice, 19(2), 617628. https://doi.org/10.1039/c7rp00230k

Bain, K., Rodriguez, J.-M. G., Moon, A., \& Towns, M. H. (2019). Mathematics in chemical kinetics: Which is the cart and which is the horse? In M. H. Towns, K. Bain, \& J.-M. G. Rodriguez (Eds.), It's just math: Research on students' understanding of chemistry and mathematics, (vol. 1316, pp. 25-46). https:// doi.org/10.1021/bk-2019-1316.ch003

Becker, N., \& Towns, M. (2012). Students' understanding of mathematical expressions in physical chemistry contexts: An analysis using Sherin's symbolic forms. Chemistry Education Research and Practice, 13(3), 209-220. https://doi.org/10.1039/C2RP00003B

Bialek, W., \& Botstein, D. (2004). Introductory science and mathematics education for 21 st-century biologists. Science, 303(5659), 788-790. https://doi.org/10.112 6/science. 1095480.

Bing, T. J., \& Redish, E. F. (2007). The cognitive blending of mathematics and physics knowledge. AlP Conference Proceedings, 883, 26-29. https://doi.org/1 $0.1063 / 1.2508683$

Bing, T. J., \& Redish, E. F. (2008). Symbolic manipulators affect mathematical mindsets. American Journal of Physics, 76(4), 418-424. https://doi.org/10.111 9/1.2835053

Bing, T. J., \& Redish, E. F. (2009). Analyzing problem solving using math in physics: Epistemological framing via warrants. Physical Review Special Topics - Physics Education Research, 5(2), 020108. https://doi.org/10.1103/PhysRevSTPER.5.020108.

Brush, S. G. (2015). Mathematics as an instigator of scientific revolutions. Science \& Education, 24(5-6), 495-513. https://doi.org/10.1007/s11191-015-9762-x.

Eichenlaub, M., \& Redish, E. F. (2019). Blending physical knowledge with mathematical form in physics problem solving. In G. Pospiech, M. Michelini, \& B.-S. Eylon (Eds.), Mathematics in Physics Education, (pp. 127-151).

Fauconnier, G., \& Turner, M. (1998). Conceptual integration networks. Cognitive Science, 22(2), 133-187. https://doi.org/10.1207/s15516709cog2202_1.

Hansson, L., Hansson, Ö., Juter, K., \& Redfors, A. (2015). Reality-theoretical models-mathematics: A ternary perspective on physics lessons in uppersecondary school. Science \& Education, 24(5-6), 615-644. https://doi.org/10.1 007/s11191-015-9750-1.

Kapon, S. (2016). Unpacking Sensemaking. Science Education, 101(1), 165-198. https://doi.org/10.1002/sce.21248.

Kuo, E., Hull, M. M., Gupta, A., \& Elby, A. (2013). How students blend conceptual and formal mathematical reasoning in solving physics problems. Science Education, 97(1), 32-57. https://doi.org/10.1002/sce.21043.

Lazenby, K. \& Becker, N. M. (2019). A modeling perspective on supporting students' reasoning with mathematics in chemistry. In M. H. Towns, K. Bain, \& J.-M. G. Rodriguez (Eds.), It's Just Math: Research on Students' Understanding of Chemistry and Mathematics, (vol. 1316, pp. 9-24). https://doi.org/10.1021/bk-2 019-1316.ch002.

Li, Y., \& Schoenfeld, A. H. (2019). Problematizing teaching and learning mathematics as "given" in STEM education. International Journal of STEM Education, 6(1). https://doi.org/10.1186/s40594-019-0197-9.

Lythcott, J. (1990). Problem solving and requisite knowledge of chemistry. Journal of Chemical Education, 67(3), 248-252. https://doi.org/10.1021/ed067p248.

Marton, F., Runesson, U., \& Tsui, A. B. M. (2004). The space of learning. In F. Marton, \& A. B. M. Tsui (Eds.), Classroom Discourse and the Space of Learning, (pp. 3-42). https://doi.org/10.4324/9781410609762.

NGSS Lead States (2013). Next generation science standards: For states, by states. Washington, DC: The National Academies Press. 
Odden, T. O. B., \& Russ, R. S. (2019). Defining sensemaking: Bringing clarity to a fragmented theoretical construct. Science Education, 103, 187-205. https://doi. org/10.1002/sce.21452.

Redish, E. F., \& Kuo, E. (2015). Language of physics, language of math: Disciplinary culture and dynamic epistemology. Science \& Education, 24(5-6), 561-590. https://doi.org/10.1007/s11191-015-9749-7.

Rittle-Johnson, B., \& Schneider, M. (2015). Developing conceptual and procedural knowledge of mathematics. In Oxford Handbook of Numerical Cognition, (pp. 1118-1134). Oxford: Oxford University Press.

Schoenfeld, A. H. (1992). Learning to think mathematically: Problem solving, metacognition, and sense making in mathematics. In Handbook for Research on Mathematics Teaching and Learning, (pp. 334-370).

Schuchardt, A. M. (2016) Learning biology through connecting mathematics to scientific mechanisms: Student outcomes and teacher supports. Doctoral dissertation, University of Pittsburgh, Pittsburgh, PA.

Schuchardt, A. M., \& Schunn, C. D. (2016). Modeling scientific processes with mathematics equations enhances student qualitative conceptual understanding and quantitative proglem solving. Science Education, 100(2), 290-320.

Stewart, J. (1983). Student problem solving in high school genetics. Science Education, 67(4), 523-540.

Taasoobshirazi, G., \& Glynn, S. M. (2009). College students solving chemistry problems: A theoretical model of expertise. Journal of Research in Science Teaching, 46(10), 1070-1089. https://doi.org/10.1002/tea.20301.

Tuminaro, J., \& Redish, E. F. (2007). Elements of a cognitive model of physics problem solving: Epistemic games. Physical Review Special Topics Physics Education Research, 3, 020101. https://doi.org/10.1103/ PhysRevSTPER.3.020101.

Yin, R. K. (2017). Case study research and applications: Design and methods, (6th ed., ). Thousand Oaks: Sage publications.

Zhao, F., \& Schuchardt, A. S. (in press). Development of the Sci-Math Sensemaking Framework: Categorizing Sensemaking of Mathematical Equations in Science. International Journal of STEM Education.

\section{Publisher's Note}

Springer Nature remains neutral with regard to jurisdictional claims in published maps and institutional affiliations.

\section{Submit your manuscript to a SpringerOpen ${ }^{\circ}$ journal and benefit from:}

- Convenient online submission

- Rigorous peer review

- Open access: articles freely available online

High visibility within the field

- Retaining the copyright to your article

Submit your next manuscript at $\boldsymbol{\nabla}$ springeropen.com 